\title{
Relationship Between Intermittent Hypoxia, Nocturnal Voiding and Sleep Related Breathing Disorders
}

\begin{abstract}
MARINA RUXANDRA OTELEA ${ }^{1}$, MIHAELA TRENCHEA ${ }^{2 *}$, CORINA ZUGRAVU1,3, RAZVAN HAINAROSIE ${ }^{1}$, ALEXANDRU STEFAN RASCU ${ }^{1,4}$, CRISTIAN DRAGOS STEFANESCU ${ }^{1,5 *}$

${ }^{1}$ University of Medicine and Pharmacy Carol Davila, 37, Dionisie Lupu Str., 020021, Bucharest, Romania

2 Ovidius University of Constanta, Medicine Faculty, 124 Mamaia Blvd, 900527, Constanta, Romania

${ }^{3}$ National Institute of Public Health, 1-3 Doctor Leonte Anastasievici, 050463, Bucharest, Romania

${ }^{4}$ Clinical Hospital Prof. Dr. Th. Burghele, 20, Panduri Road, 050653, Bucharest, Romania

5"Gen. Dr. Aviator Victor Anastasiu National Institute of Aeronautical and Spatial Medicine, 88th Mircea Vulcanescu Str., 010825 , Bucharest, Romania

Nocturia, cardio-vascular diseases and diabetes are frequent in patients with sleep related breathing disorders. In this study, we had analyzed the influence of the intermittent hypoxia on nocturia prevalence and found that cardio-vascular diseases, obesity, age and apnea hypopnea indexpredict $27.1 \%$ of nocturia's variance (Nagelkerke $R$ square- $=.271, \chi^{2}=68.35$ ). In $\mathrm{AHI}<28$, the chance of nocturia is $50 \%$ and the difference dependents on the presence or absence of the cardio-vascular diseases. For values of AHI >28, the risk of nocturia becomes independent of the presence of the cardio-vascular disease.
\end{abstract}

Keywords: apnea-hypopnea index, nocturia, sleep related breathing disorders, cardio-vasculardisease, ENT

Nocturia is defined as the complaint that the individual has to wake at night one or more times for voiding (i.e. to urinate) [1]; depending on the clinical threshold included in the definition (at least 1 or 2 voiding by night), the incidence varies around 50 , or $20 \%$, respectively, in both sexes [2]. The pathogenesis of nocturia is very complex involving multiple neurohormonal loops and local dysfunctions. Regardless the etiology, a common consequence of nocturia is sleep interruption and the circadian dysregulation. In the kidney, the circadian clock regulates endothelin, aquaporin and the expression of $\mathrm{Na}$ epithelial channels [3]. The bladder cells are also subject of the circadian genes influence in the lumbar spinal cord, detrusor, sphincter and urothelium [4]. Based on these research findings, nocturia has been considered a disease of circadian dysfunction.

Sleep related breathing disorders (SRBD) refers to a spectrum of breathing abnormalities occurring during sleep; beside obstructive sleep apnea (OSA), that is the most frequently diagnosed SRBD, upper airway resistance syndrome (UARS), central sleep apnea (CSA) and obesity hypoventilation syndrome (OHS) are included. Arousals, various levels of desaturations and sleep fragmentations are the common findings of these disorders. From the perspective of sleep interruption, nocturia and SRBD might share some pathophysiological mechanisms. Studies have show $n$ that interrupted sleep itself is a potentially harmful and debilitating factor [5], that increases the risk of hypertension, diabetes, mental diseases, malignancies and accidents [6], all having a possible influence on the prevalence of the nocturia. In this regard, we conducted a cross sectional study in patients, when first diagnosed with SRBD, to identify the factors that relates to the prevalence of nocturia.

\section{Experimental part}

This study presents the analysis of 326 patients with SRBD, referred, during 2012-2016, to the Somnology
Laboratory of Constanta Clinical Pneumophthisiology Hospital. The research comprised a standard questionnaire, clinical examination, ENT examination and polygraphy test. Before entering into the study, the patients signed an informed consent form. Diurnal sleepiness was evaluated by Epworth score, considering excessive daytime sleepiness (EDS) if Epworth score was $\geq 18$ points. The body mass index (BMI) was calculated as weight $(\mathrm{kg}) /$ height $(\mathrm{m})^{2}$. International Diabetes Federation (IDF) criteria were used to define the normal values for WC [7]. The neck circumference (NC) was measured in a horizontal plan, below the laringeal proeminence. Abnormal values were considered if $\mathrm{NC}$ was $>43 \mathrm{~cm}$ in women and $>45$ $\mathrm{cm}$ in men. A polygraphy testing was conducted with a STARDUST II RESPIRONICS polygraph and the apneahypopnea index (AHI) and the desaturation parameters were extracted from the polygraph datasheets. Apnea was counted if a cessation of flow of $\geq 10$ s was noticed, while hypopnea was considered if airflow was reduced by $\geq 30 \%$ with a desaturation $\geq 3 \%$ from baseline. The BRSD were divided following the current recommendations of the American Academy of Sleep Medicine: OSA, if AHI > 5/h, UARS if $A H I<5 / h$ and the minimal peripheral $O$, saturation $\left(\right.$ minSpO $\left._{2}\right) \geq 92 \%$, CSA if AHI $\geq 5$ without respiratory effort, and $\mathrm{OHS}$ if $\mathrm{BMI}$ was $\geq 30 \mathrm{~kg} / \mathrm{m}^{2}$ and the average peripheral

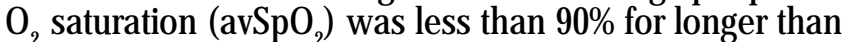
$30 \%$ of the sleep duration [8]. The severity of AHI was classified as mild if $\mathrm{AHI}=5-14$, moderate if $\mathrm{AHI}=15-29$ and severe if $\mathrm{AHI}>30$. Parameters of the peripheral $\mathrm{O}_{2}$ saturation (avSpO2, minSpO , and time spent below $90 \%$ of the oxygen saturation level during sleep, TS $\mathrm{SpO}_{2} 90 \%$ )were measured by pulse oximetry and authomatically computed by the polygraph software for the total night sleep duration.

The statistical analysis was performed bySSPS software (Stat Plus for Mac, Analyst Soft Inc. Version V6, 2016). The threshold for the statistical significance was set at $95 \%$. Categorical variables were compared using $\chi^{2}$ test, and

*email: mtrenchea79@yahoo.com, Phone:0721979880; cristlandragos@hotmail.com, Phone:0730047455 
numerical variables with Anova or Mann Whitney test, according to the type of distribution. Lastly, a binary logic regression (enter method) was computed, with nocturia as a dependent variable, and age, BMI categories, parameters of the peripheral $\mathrm{O}_{2}$ saturation and comorbidities as independent ones.

\section{Results and discussions}

From the initial 326 patients, a diagnosis of SRBD was assessed among 306 subjects, of which the majority ( 72.5 $\%)$ were men. None of these patients had a previous documented renal failure. Nocturia was mentioned by a great majority $(n=184 / 306)$. The prevalence of nocturia increased with aging (fig.1), ( $F=32416.1078, p<0.001)$ both for men and women $\left(\chi^{2}=1.3800\right.$, $p=0.2401)$.Nocturnal respiratory symptoms were present in all patients, but only the reported nocturnal apnea and awakenenings were associated to nocturia $\left(\chi^{2}=6.4809\right.$, $p=0.0391$ for apnea, and $\chi^{2}=8.0945, p=0.0004$ for awakenings). Reported nocturnal apnea was notcorrelated with age $(\mathrm{F}=0.2205, p=0.6392)$ or gender $\left(\chi^{2}=2.2038\right.$, $p=0.3492)$. Awakenings were directly related to age $(F=7.531, p=0.0064)$ and influenced by gender, being more frequent in women (66.67\%) than in men (47.75\%) $\left(\chi^{2}=8.095, p=0.0044\right)$. The relation between awakenings and nocturia was maintained after age adjustment.

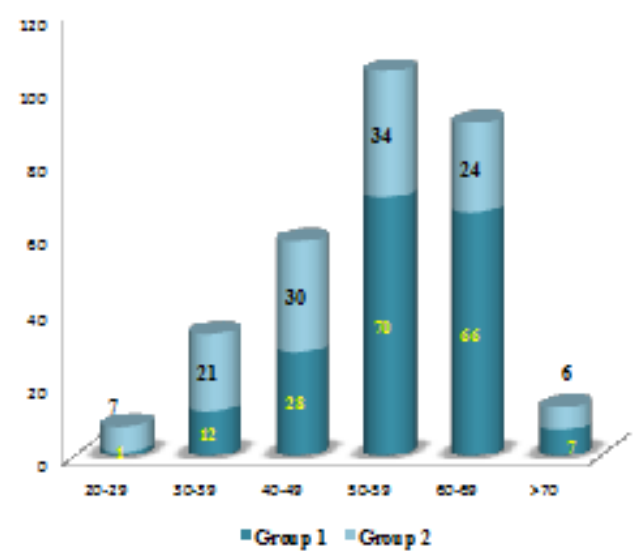

Fig 1. Age distribution in the study groups

The average $\mathrm{BMI}, \mathrm{WC}$ and $\mathrm{NC}$ in men were significantly higher than in women $(p<0.001)$. A direct relation betw een each of the anthropometric measures (BMI, WC, $\mathrm{NC}$ ) and nocturia was noticed ( $p<0.001)$, independent to age, but influenced by gender.

The nocturia prevalence according to BRSD by decades of age is represented in figure 2 . There was no significant difference in the prevalence of BRSD by gender $\left(\chi^{2}=1.38001, p=0.2401\right)$.

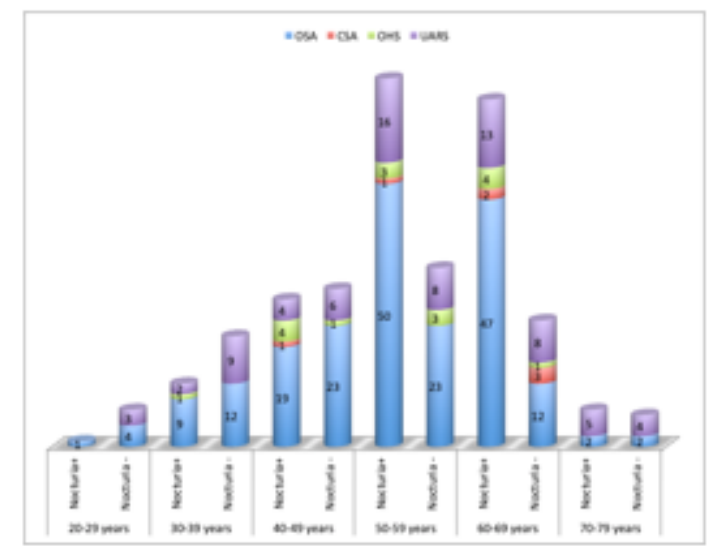

Fig 2. Nocturia by type of BRSD and decades of age
The prevalence of the cardio-vascular diseases in this population was high $(65.34 \%)$ and, after age adjustment, a significant association with nocturia $\left(\chi^{2}=43.0454\right.$, $p=0.5 .34839 E-11$ ) was found. There was also a significant difference in the number of patients with T2D that reported nocturia $\left(\chi^{2}=9.15284, p=0.00248\right)$ as the majority $(69.56 \%)$ had this symptom; no influence by age was noticed. All parameters reflecting the low levels of peripheral oxygen saturation were significantly associated to nocturia (table 1$)$ and age $(U=7649, p=0.000)$.

Table 1

THE OXYGEN DESATURATION PARAMETERS RELATION WITH NOCTURIA

\begin{tabular}{|l|l|l|}
\hline Desaturation & Mann & P \\
parameter & Whitney U & \\
\hline AHI & 8761 & 0.001 \\
\hline ODI & 8877 & 0.002 \\
\hline Av SpO & 9108 & 0.005 \\
\hline Min $\mathrm{SpO}_{2}$ & 9526 & 0.024 \\
\hline TS_Sp O & 8698 & 0.001 \\
\hline
\end{tabular}

$\mathrm{AHI}=$ apnea- hypopnea index; $\mathrm{ODI}=$ oxygen desaturation index;

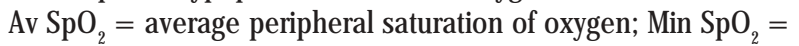
minimal peripheral saturation in $\mathrm{O}_{2} ; \mathrm{TS} \mathrm{Sp} \mathrm{O}_{2}=$ time spent below $90 \%$ of the oxygen saturation level during sleep

Although there was no difference by gender or smoking status, mostly patients in group 1were older than 50 years (74\%), with an almost equal distribution in both groups between the fifth, sixth and seventh decade of age (table 2). The anamnesis revelead differences in the nocturnal symptoms such as more frequent nocturnal awakenings $\left(\chi^{2}=30.033, p=4.24677 \mathrm{E}-8\right)$ and reported apneas $\left(\chi^{2}\right.$ $=6.4809, p=0.0391$ ), concordant with a higher average of the Epworths score. Excessive diurnal sleepiness was present in 20\%, significantly more prevalent in group 1 as compared to the group 2 ( $34.31 \%$ vs. $29.09 \%)\left(\chi^{2}=7.9778\right.$, $p=0.0047$ ). All of the measured anthropometric characteristics were higher in the nocturia group. The distribution according to $\mathrm{AHI}$, was different between the 2 groups $\left(\chi^{2}=18.1377 p=0.0004\right)$. Patients in group 1 were more frequently in the lowest $25 \%$ percentile of the avSpO and above the $75 \%$ percentile of the TS_SpO,90\% (fig 3). These distributions were statistically significant $\left(\chi^{2}=\right.$ $10.1154, p=0.0064$ for the avSpO and $\chi^{2}=10.2593 p$ $=0.0059$ for the duration of TS $\mathrm{SpO}_{2} 90 \%$ ). Results of the regression model of nocturia in $\mathrm{S} \overline{\mathrm{B}} \mathrm{BD}$ are presented in table 3.Among these statistically significant variables, the greatest influence came from cardio-vascular diseases, followed by obesity (versus normal weight), age and AHI. The final model predicted $27.1 \%$ of nocturia's variance (Nagelkerke R square- $=.271$ ); model $\chi^{2}$ is 68.35.The greater the value of $\mathrm{AHI}$ is, the greater the chance of the intermittent hipoxia can be and the less is the cardiovascular disease influence on nocturia. In AHI less than 28 , the chance of nocturia is $50 \%$ and the difference dependents on the presence or absence of the cardiovascular diseases. For values of $\mathrm{AHI}$ above 28 , the risk of nocturia is significantly higher and becomes independent of the presence of the cardio-vascular diseases.

As confirmed by us, nocturia is a frequent symptom in SRBD patients, with a very important impact on the quality of life. There is a bilateral relation between nocturia and SRBD: awakenings for voiding lead to sleep fragmentation, 
Table 2

COMPARISON BETWEEN PATIENTS WITH NOCTURIA AND PATIENTS WITHOUT NOCTURIA

\begin{tabular}{|c|c|c|c|c|}
\hline & Nocturia $(+)$ & Nocturia $(-)$ & Total & $\mathrm{p}$ \\
\hline Age (average $\pm \mathrm{SD}$ ) & $55.95 \pm 9.58$ & $49.43 \pm 12.41$ & $53.35 \pm 11.24$ & $<0.0001$ \\
\hline Gender (M/F) & $129 / 55$ & $93 / 29$ & $222 / 84$ & 0.2401 \\
\hline $\begin{array}{l}\text { Smokers (active/exsmokers/never } \\
\text { smokers) }\end{array}$ & $64 / 63 / 57$ & $51 / 39 / 32$ & $115 / 102 / 89$ & 0.4394 \\
\hline Epworth score (average + SD) & $9.27 \pm 5.39$ & $7.24 \pm 4.62$ & $8.46 \pm 5.19$ & 0.0011 \\
\hline \multicolumn{5}{|l|}{ Antropometric measures } \\
\hline BMI (average + SD) & $34.99 \pm 6.68$ & $32.54 \pm 6.06$ & $34.01 \pm 6.54$ & 0.0003 \\
\hline WC (average + SD) & $110.52=10.91$ & $106.58 \pm 9.26$ & $108.95 \pm 10.45$ & 0.0026 \\
\hline $\mathrm{NC}$ (average + SD) & $43.77 \pm 3.63$ & $42.39 \pm 3.20$ & $43.22 \pm 3.52$ & 0.0013 \\
\hline Type of SRBD & & & & 0.0345 \\
\hline OSA & 128 & 76 & 204 & \\
\hline UARS & 40 & 38 & 78 & \\
\hline CSA & 4 & 6 & 10 & \\
\hline OHS & 12 & 2 & 14 & \\
\hline \multicolumn{5}{|l|}{ Comorbidities } \\
\hline Chronic lung disease (Yes/No) & $64 / 120$ & $38 / 84$ & $102 / 204$ & 0.5089 \\
\hline Cardio-vascular diseases (Yes/No) & $147 / 37$ & $53 / 69$ & $200 / 106$ & $<0.0001$ \\
\hline T2DM (Yes/No) & $41 / 143$ & $11 / 111$ & $52 / 254$ & 0.0025 \\
\hline Psychiatric disease (Yes/No) & $5 / 179$ & $4 / 118$ & $9 / 297$ & 0.7760 \\
\hline ENT disorders (Yes/No) & $47 / 137$ & $39 / 83$ & $86 / 220$ & 0.2209 \\
\hline \multicolumn{5}{|l|}{$\begin{array}{l}\text { Severity of SRBD and } \mathrm{O}_{2} \text { saturation } \\
\text { indexes }\end{array}$} \\
\hline AHI (average + SD) & $39.20=27.56$ & $28.58 \pm 24.43$ & $34.96 \pm 26.82$ & 0.0011 \\
\hline Av SpO2 (average + SD) & $91.54 \pm 4.19$ & $92.66 \pm 3.44$ & $91.99 \pm 3.94$ & 0.0005 \\
\hline Min SpO2 (average + SD) & $76.81 \pm 10.54$ & $79.59 \pm 10.63$ & $77.92 \pm 10.65$ & 0.0258 \\
\hline TS_SpO $290 \%$ (average + SD) & $13.61 \pm 14.17$ & $8.94 \pm 10.60$ & $11.75 \% \pm 13.05$ & 0.0008 \\
\hline
\end{tabular}

BMI = body mass index; WC = waist circumference; $\mathrm{NC}=$ neck circumference; SRBD = sleep related breath disorders; OSA = obstructive sleep apnea; UARS = upper airways resistance syndrome; CSA = central sleep apnea; OHS = obesity hypoventilation syndrome; T2DM= type 2 diabetes; $\mathrm{ENT}=$ ear nose and throat; $\mathrm{AHI}=$ apnea- hypopnea index; $\mathrm{ODI}=$ oxygen desaturation index; $\mathrm{Av} \mathrm{SpO}=$ average peripheral saturation of oxygen; $\mathrm{Min} \mathrm{SpO}_{2}=$ minimal peripheral saturation in $\mathrm{O}_{2}$; TS_Sp $\mathrm{O}_{2}=$ time spent below $90 \%$ of the oxygen saturation level during sleep

\begin{tabular}{|l|l|l|l|l|}
\hline & \multicolumn{4}{|c|}{$95 \%$ Cl for odds ratio } \\
\hline & $\mathrm{B}(\mathrm{SE})$ & Lower & Odds ratio & upper \\
\hline Age $^{8}$ & $-.40(.015)$ & 0.961 & 0.934 & 0.989 \\
\hline $\mathrm{AHI}^{*}$ & $-0.015(0.007)$ & 0.986 & 0.972 & 0.999 \\
\hline Cardio-vascular diseases $^{8}$ (present vs absent) & $-1,038(0.331)$ & 0.354 & 0.185 & 0.677 \\
\hline T2D (present vs absent) & $-0.428(0.405)$ & 0.652 & 0.295 & 1.440 \\
\hline Obese vs overweight & $0.304(0.662)$ & 1.355 & 0.371 & 4.958 \\
\hline Obese vs normal wight $^{*}$ & $0.840(0.328)$ & 2.316 & 1.217 & 4.409 \\
\hline avSpO $_{2}$ & $-0,52(0.051)$ & 0.949 & 0.858 & 1.050 \\
\hline TS_SpO $_{2} 90 \%$ & $-0.13(0.015)$ & 0.987 & 0.958 & 1.017 \\
\hline constant $^{2}$ & $7.91(4.99)$ & & & \\
\hline
\end{tabular}

$\mathrm{AHI}=$ apnea-hypopnea index; $\mathrm{T2D}=$ type 2 diabetes; $\mathrm{avSpO}_{2}=$ average peripheral saturation in $0_{2}$; TS $\mathrm{SpO}_{2} 90 \%=$ time spent below $90 \%$ of the oxygen saturation level during sleep $* p<0.01$

impairing the overall quality of sleep, already affected by the SRBD. There is also evidence that control of desaturation in OSA reduces the number of nocturnal voiding and the night time urine volume [9].

The high prevalence of nocturia (60.01\%) was confirmed in this study, in accordance to previous reports [10-12]. Nocturia showed a positive association with other nocturnal awakenings, self reported apnea episodes and diurnal somnolescence, all having an impact on the quality of life. Intermittent hypoxia, hypercapnia and acidosis during the upper airways collapse trigger the pulmonary vasoconstriction, the chemoreceptors and the sympathetic stimulation, particularly in the late expiration phase[13]. The coexistent hypoxia and hypercapnia maintain the high blood pressure and the heart rate increase for more than 15 min even in healthy voluntiers [14]. The extreme negative thoracic pressure raises the venous return, while the transmural pressure resulting from the inefficient

diaphragmatic contractions, affects the left ventricular afterload. Ventricular stretch and acidosis stimulates the atrial natriuretic peptide (ANP) release that promotes diuresis. The false hypovolemic signal increases the AVP and aldosteron levels and accumulate water and sodium. A putative model of these complex pathophysiological loops, integrating the main triggers (hypoxemia, hypercapnia and acidosis) to the neuro-hormonal factors is presented in figure 4.

In normal individuals, arginine vasopressin (AVP) has a circadian rhytm of secretion and release; the release fluctuates during the day time, decreases in the evening and reaches the peak between 2-4 a.m.; this circadian rhytm seams to disappear after 50 years of old [15]. The lack of nocturnal overproduction of AVP explains, in part, the increase of the nocturia prevalence with age, but age must not be seen as the only influencing factor of the AVP secretion. Chronic changes in hypothalamic supra- 


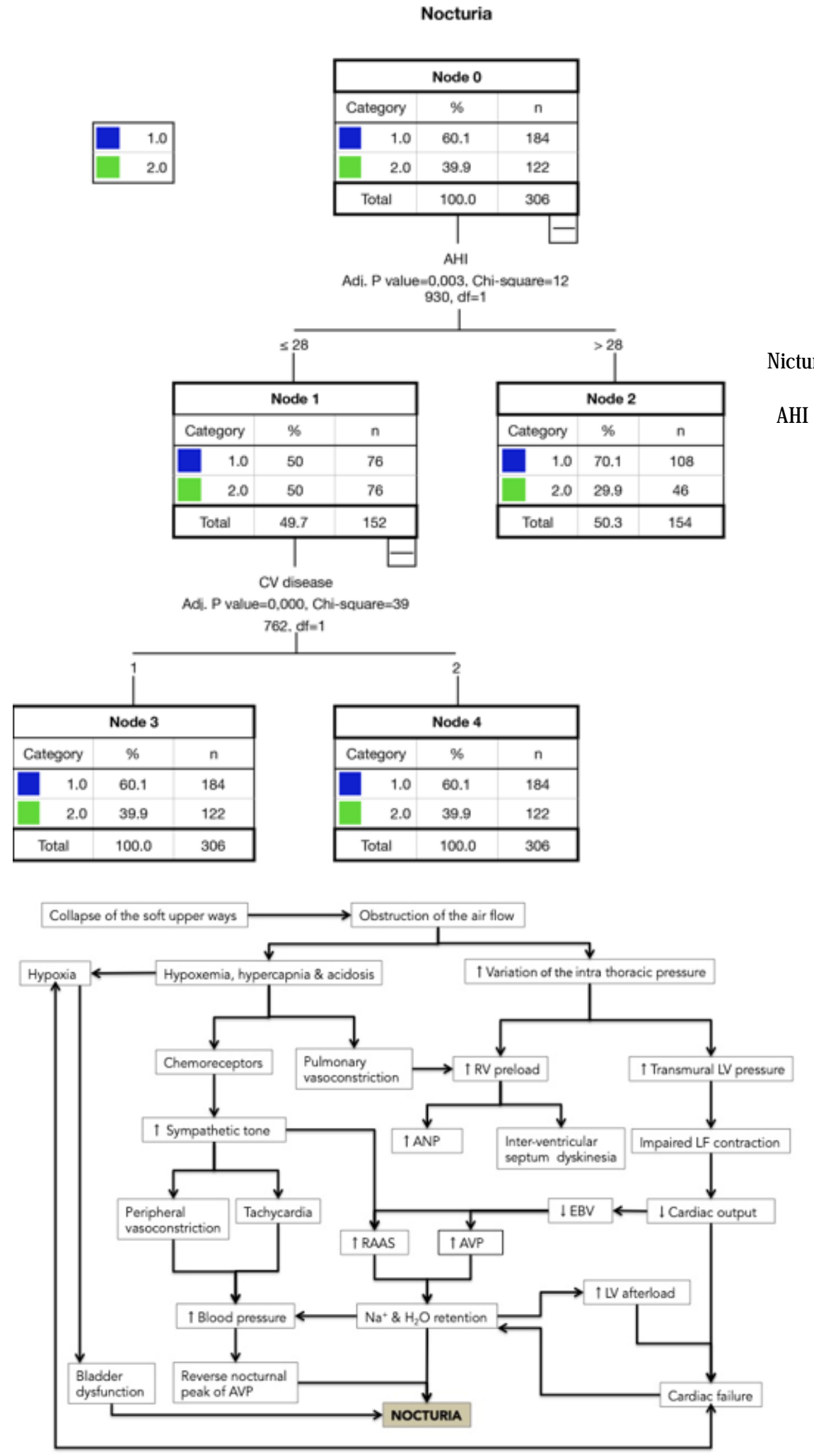

Fig 3. The predictors of nocturia.

Nicturia variable was coded with 1 for presence of the nocturia and 2 for absence of the nocturia.

$\mathrm{AHI}=$ apnea hypopnea index; CV disease = cardiovascular disease

Fig 4. Pathophysiological mechanisms of nocturia in breath related sleep disorders. ANP = atrial natriuretic peptide; AVP = arginine vasopressin; RAAS = renin angiotensin system;

$\mathrm{EBV}=$ effective blood volume; $\mathrm{RV}=$ right ventricle; LF left ventricle

chiasmatic nuclei (SCN) have been observed in hypertension, with a significant reduction of the content in AVP [16].In cardiac failure, the reduction in effective circulationg blood volume raises the plasma level of AVP[17]. AVP aggravates both systolic (by vasoconstriction) and dyastolic (by preload) stress and contributes to natriuretic peptides release. High plasma co-peptin, released together with the AVP, significantly associates to microalbuminuria, independent of age and with decreased renal filtration rate [18]. In fact, the AVP increases during night time only in severe sleep apnea, if $\mathrm{AHI}$ is $>15[19]$, showing that these pathophysiological mechanisms become proeminent in repetead intermittent obstruction of the airflow. These neuro-hormonal modifications are just amplified by the intermittent desaturation, as confirmed by others [10-12]. The regression model derived from our results is underlying the importance of the co-existent cardio-vascular disease in patients presenting with nocturia.

In a previous communication, based on smaller group in which more blood tests were performed, we have reported that the desaturation level and the $\mathrm{HbAlC}$ are related [20]. Medical literature provides contradictory results on the relation between diabetes and nocturia, although some direct pathogenic mechanisms were demonstrated [21-23]. In SRBD studies an association was 
not found [11] unless a certain degree of severity of the intermittent obstruction and/or of the desaturation were considered [24]. In our final regression model the influence was no more significant. We do not have a conclusive explanation of this finding, but itmight be related to factors that we have not assessed, such as the duration and the control of the T2D.

Our results emphasize that the severity of desaturation is a key factor for nocturia, as it is shown in other pulmonary disorders $[25,26]$. The model derived from our data is consistent with previously found predictors of nocturia in SRBD (age, BMI, hypertension and diabetes) [10,27] but the influence of the other predictors lost their significance, if $\mathrm{AHI}$ became higher than 28 . This $\mathrm{AHI}$ value is at the borderline between the classic 3 degrees of severity of SRBD. In this context, it is of interest to notice that when not associated with intermittent desaturation, high blood pressure or diabetes were not significantly related to the nocturnal polyuria severity and to the number of nocturnal voidings, recorded by the $24 \mathrm{~h}$ frequency and volume chart monitoring [24]. Lung function reduction associated with the abdominal type of the fat distribution might also contribute to worsening desaturation levels. Lung function was shown to relate to work disability [28] and, as in other lung disorders, to the quality of life [29] and should be considered in patients with high AHI.

\section{Conclusions}

The severity of SRBD influences nocturia and nocturia induces awakenings, which affect the duration and sleep architecture. Age, high desaturation, obesity and cardiovascular disease explain almost a third of the nocturia's variance. Intermittent hypoxemia is an important factor of influence of the nocturia prevalence. Particularly if the frequency, as assessed by the apnea-hypopnea episodes, is higher than $28 / \mathrm{h}$, the desaturation is a significant contributor of the SRBD - nocturic phenotype.

\section{References}

1.Van KERREBROECK, P., ABRAMS, P., CHAIKIN, D., DONOVAN, J., FONDA, D., JACKSON, S., J ENNUM, P., JOHNSON, T., LOSE, G., MATTIASSON, A., ROBERTSON, G., WEISS, J., STANDARDISATION SUBCOMMITTEE OF THE INTERNATIONAL CONTINENCE SOCIETY., Neurourol Urodyn., 21, nr 2, 2002, p. 179

2.IRWIN, D.,E., MILSOM, I., HUNSKAAR, S., REILLY, K., KOPP, Z., HERSCHORN, S., COYNE, K., KELLEHER, C., HAMPEL, C., ARTIBANI, W., ABRAMS, P., Eur Urol, $50 \mathrm{nr}$ 6, 2006, p.1306

3.ZUBER, A.,M., CENTENO, G., PRADERVAND, S., NIKOLAEVA, S., MAQUELIN, L., CARDINAUX, L., BONNY, O., FIRSOV, D. Proc Natl Acad Sci U S A., 106, nr 38, 2009, p.16523

4.NOH, J.,Y., HAN, D.,H., KIM, M.,H., KO, I.,G., KIM, S.,E., PARK, N., CHOE, H.,K, KIM, K.,H., KIM, K., KIM, C., J., CHO, S. Exp Mol Med., 46 $\mathrm{nr} 3,2014$, p.e81
5.RASCU, A., ARGHIR, O.C., OTELEA, M., Rom J Legal Med., 24, nr 2, 2016, p.118

6.KENDZERSKA, T., GERSHON, A.,S., HAWKER, G., Am J Respir Crit Care Med., 190, nr 2, 2014, p. 218

7.ALBERTI, K.,G., ZIMMET, P., SHAW, J., IDF Epidemiology Task Force Consensus Group., Lancet, 366 nr. 9491, 2005, p.1059

8.SATEIA, M.IJ., Chest, 146, nr. 5, 2014, p.1387

9.WANG, T., HUANG, W., ZONG, H., ZHANG, Y. Int Neurourol J., 19, nr. 3, 2015, p.178

10.0ZTURA, I., KAYNAK, D., KAYNAK, H.,C., Sleep Med., 7, nr 4, 2006, p.362

11.GOYAL A, PAKHARE A, CHAUDHARY P. Lung India, 36, 2019,p.20-27 12.ROMERO, E., KRAKOW, B., HAYNES, P., ULIBARRI, V. Sleep Breath., 14, $\mathrm{nr}$ 4, 2014, p. 337

13.MULLER-RIBEIRO, F.,C.,F., GOODCHILD, A.,K., MCMULLAN, S., FONTES, M.,A.,P., DAMPNEY, R.,A.,L., Respir Physiol Neurobiol. 226, 2016, p.87-93

14.TAMISIER, R., NIETO, L., ANAND, A., CUNNINGTON, D., WEISS, J.,W., Respir Physiol Neurobiol. 141, nr.2, 2014, p.145

15.BUIJS R.M., SWAAB D.F. Handbook of Clinical Neurology, Vol. 117 (3rd series) Autonomic Nervous System., 2013 Elsevier B.V., Oxford, United Kingdom, 2013, pp 175-191

16.GONCHARUK, V.,D., VAN HEERIKHUIZE, J., DAI, J.,P., SWAAB, D.,F., BUIJ S, R.,M., ., Comp Neurol, 431, nr 1, 2001, p.320

17.LANFEAR, D.,E., SABBAH, H.,N., GOLDSMITH, S.,R., GREENE, S., ., AMBROSY, A.,P., FOUGHT, A., ., KWASNY, M., ., SWEDBERG, K., YANCY, C.,W., KONSTAM, M.,A., MAGGIONI, A.,P., ZANNAD, F., GHEORGHIADE, M., Circ Heart Fail., 6, nr 1, 2013, p.47

18.MORGENTHALER, N.,G.,Congest Heart Fail, 16, 2010, p.S37-S44. 19.UMLAUF, M.,G., CHASENS, E.,R., GREEVY, R.,A., ARNOLD, J., BURGIO, K.,L., PILLION, D., .,. Sleep., 27, nr 1, 2004, p.139

20.OTELEA, M.R., TRENCHEA, M., ARGHIR, O.C., VELESCU, L., DANTES, E., BECHIR, E.S., ELSAAFIN, M., RASCU, A., Rev. Chim. (Bucharest)., 69, no. 1, 2018, p.282

21.KALANI, M., Vasc Health Risk Manag.,4, nr.5, 2008, p.1061

22.ANTON, A., TOFOLEAN, D.E.,Sleep Med., 40, suppl1, 2017, p. e16 23.MOISE, L.,G., MARTA, D.,S., RASCU, A., MOLDOVEANU, E. Acta Endo (BuC),14, nr 1, 2018, p. 36

24.NASSAU, D., AVULOVA, S., FRIEDMAN, F.M., WEISS, J .,P, BLAIVAS, J.G., JAMA Surg., 2015;150(2):125-128. doi:10.1001/jamasurg.2014.1332 25.BUDIN, C.,E., MAIEREAN, A.,D., IANOSI, E.,S., SOCACI, A., BUZOIANU, A.D., ALEXESCU, T.G., OLTEANU,M., RUSU, E., MOLDOVAN, C.A., NEMES, R.M. Rev Chim. (Bucharest), 70, no. 2, 2019, p. 449

26.MIHAILOV, C., JIMBOREAN, G., RASCU, A., ARGHIR, O.,C.,.J Environ Prot Ecol.17, n5 4, 2016, p.1523

27.AYIK, S., BAL, K., AKHAN, G.,Turk J Med Sci, 44, nr 2, 2014, p. 249 28.STENDARDO, M., CASILLO, V., SCHITO, M., BALLERIN, L., STOMEO, F., VITALI, E., NARDINI, M., MAIETTI, E., BOSCHETTO, P., PLOS One., 13, nr 7, 2018, p. e0201045.

29.OTELEA, M.R., ARGHIR, O.C., ZUGRAVU. C., NAGHI, E., ANTONIU, S., RASCU, A., Rev. Chim. (Bucharest), 69, no. 2, 2018, p. 346

Manuscript received: 22.08 .2018 